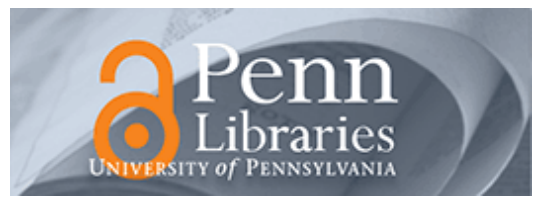

University of Pennsylvania ScholarlyCommons

March 2001

\title{
Facilitating Communication Across Lines of Political Difference: The Role of Mass Media
}

Diana C. Mutz

University of Pennsylvania, mutz@sas.upenn.edu

Paul S. Martin

University of Oklahoma

Follow this and additional works at: https://repository.upenn.edu/asc_papers

\section{Recommended Citation}

Mutz, D. C., \& Martin, P. S. (2001). Facilitating Communication Across Lines of Political Difference: The Role of Mass Media. American Political Science Review, 95 (1), 97-114. Retrieved from

https://repository.upenn.edu/asc_papers/125

NOTE: At the time of publication, the author Diana C. Mutz was affiliated with Ohio State University. Currently, she is a faculty member of the Annenberg School for Communication.

This paper is posted at ScholarlyCommons. https://repository.upenn.edu/asc_papers/125

For more information, please contact repository@pobox.upenn.edu. 


\title{
Facilitating Communication Across Lines of Political Difference: The Role of Mass Media
}

\author{
Abstract \\ We use national survey data to examine the extent to which various sources of political information \\ expose people to dissimilar political views. We hypothesize that the individual's ability and desire to \\ exercise selective exposure is a key factor in determining whether a given source produces exposure to \\ dissimilar views. Although a lack of diverse perspectives is a common complaint against American news \\ media, we find that individuals are exposed to far more dissimilar political views via news media than \\ through interpersonal political discussants. The media advantage is rooted in the relative difficulty of \\ selectively exposing oneself to those sources of information, as well as the lesser desire to do so, given \\ the impersonal nature of mass media.
}

\section{Comments}

NOTE: At the time of publication, the author Diana C. Mutz was affiliated with Ohio State University. Currently, she is a faculty member of the Annenberg School for Communication. 


\title{
Facilitating Communication across Lines of Political Difference: The Role of Mass Media
}

\author{
DIANA C. MUTZ The Ohio State University \\ PAUL S. MARTIN University of Oklahoma
}

\begin{abstract}
$W$
e use national survey data to examine the extent to which various sources of political information expose people to dissimilar political views. We hypothesize that the individual's ability and desire to exercise selective exposure is a key factor in determining whether a given source produces exposure to dissimilar views. Although a lack of diverse perspectives is a common complaint against American news media, we find that individuals are exposed to far more dissimilar political views via news media than through interpersonal political discussants. The media advantage is rooted in the relative difficulty of selectively exposing oneself to those sources of information, as well as the lesser desire to do so, given the impersonal nature of mass media.
\end{abstract}

$\mathbf{T}$ he extent to which people are exposed to crosscutting political viewpoints has become of increasing concern to observers of American politics. Advocates of deliberative democracy believe such exposure is essential in order for alternatives to be contrasted effectively (Fishkin 1991). Others consider exposure to dissimilar views indispensable in forming valid opinions and in learning to appreciate the perspectives of others (Arendt 1968; Benhabib 1992). Still others point to the value of exposure to cross-cutting views for purposes of establishing political legitimacy. Exposure to cross-cutting views ensures "that no one could see the end result as arbitrary rather than reasonable and justifiable, even if not what he or she happened to see as most justifiable" (Fearon 1998, 62, emphasis in original).

Exposure to conflicting views is deemed a central element-if not the sine qua non-of the kind of political dialogue needed to maintain a democratic citizenry (e.g., Barber 1984; Bellah et al. 1985; Habermas 1989). In contrast, political talk that centers on reinforcing a shared viewpoint does little to encourage deliberation on multiple perspectives or promote a public sphere (Calhoun 1988, 220; Schudson 1995). According to the most often cited proponent of communication across lines of difference, John Stuart Mill, "if the opinion is right, [people] are deprived of the opportunity of exchanging error for truth; if wrong, they lose what is almost as great a benefit, the clearer perception and livelier impression of truth produced by its collision with error" (Mill [1859] 1956, 21). Mill's statement points to two potential benefits of exposure to oppositional views, the opportunity to change one's mind and adopt a normatively better viewpoint, and the deeper understanding of one's own position acquired through confronting different perspectives. A third benefit is legitimation of an undesired outcome.

Diana C. Mutz is Professor of Political Science and Journalism and Communication, Ohio State University, Columbus, OH 43210-1373. Paul S. Martin is Assistant Professor of Political Science, University of Oklahoma, Norman, OK 73019.

This research was supported by a grant to Mutz from the Spencer Foundation and by the Center for Advanced Study in the Behavioral Sciences. We are grateful to the editor and anonymous reviewers for improving this manuscript.
To the extent that people are at least exposed to rationales for views with which they disagree, even an outcome they do not like acquires greater legitimacy.

For example, the literature on political tolerance argues that education is important because it "puts a person in touch with people whose ideas and values are different from one's own" (Stouffer 1955, 127, emphasis in original). Likewise, differences in tolerance between men and women and between urban and rural residents have been attributed to the more parochial contacts of women and rural dwellers (Nunn, Crockett, and Williams 1978; Sullivan, Piereson, and Marcus 1982). Along similar lines, authoritarianism is negatively related to diversity of experience (Altemeyer 1996; Marcus et al. 1995), and politically diverse personal networks increase awareness of oppositional viewpoints and political tolerance (Mutz 1999).

In short, both in political theory and empirical work, there is near unanimous agreement that exposure to diverse political views is good for democracy and should be encouraged. Most social scientists concur that political attitudes and opinions are formed through social interaction, political discussion, and personal reflection, and these processes are of a higher quality when people are exposed to dissimilar perspectives. Nonetheless, there is little empirical work on the contexts in which such exposure occurs. Moreover, the recent trend toward residential balkanization based on shared lifestyles heightens concerns about communication across lines of political difference in the United States. To the extent that people live among homogeneous others in self-selected enclaves, their exposure to dissimilar views may be limited.

Some theorists propose that the future of communication across lines of political difference lies in technologies that transcend geographic space. As Calhoun $(1988,225)$ argues, "in modern societies, most of the information we have about people different from ourselves comes not through any direct relationships, even the casual ones formed constantly in urban streets and shops. Rather it comes through print and electronic media." Yet, much of what is known about the structure and news gathering practices of American media suggests that they are unlikely to play a very useful role. The goal of this study is to evaluate conflicting claims 
regarding the media's contribution to cross-cutting political exposure.

We begin by reviewing relevant research on interpersonal communication and the mass media. We then use two national surveys to test the proposition that the media make a greater contribution than interpersonal networks to Americans' exposure to dissimilar political views. Drawing on survey data across different media environments, we examine three independent tests of whether selective exposure explains our finding of greater exposure to cross-cutting views through news media. The results suggest that the structure of Americans' information environments places an extraordinary burden on the mass media to bring diverse perspectives to public attention, a burden the news media may be increasingly ill-equipped to shoulder.

\section{INTERPERSONAL EXPOSURE TO DISSIMILAR POLITICAL VIEWS}

The verdict with respect to Americans' interpersonal information environments has become increasingly bleak in the last few decades. The kind of people with whom any given individual discusses politics is a function of two factors: the availability of discussion partners in one's immediate environment and the amount of selectivity exercised in the choice of partners (Huckfeldt and Sprague 1995a). Research suggests that both factors now operate primarily to produce greater homogeneity in interpersonal interactions. With respect to availability, residential patterns suggest increasingly spatially segregated living even within the heterogeneous populations of large cities, thus prompting many to argue that Americans are increasingly separated from those with political views different from their own (e.g., Calhoun 1988). ${ }^{1}$ Residential balkanization does not necessarily mean that hordes of Americans are choosing to live among people who share their political views because of those views. Indeed, few Americans assign politics such a central role in their lives. De facto selectivity is far more likely (Freedman and Sears 1965), that is, people may choose a particular location because it is convenient to local co-ops, or a golf course, or the schools they want their children to attend, and they find themselves among others who based selection on similar considerations. The initial goal may not have been politically like-minded neighbors, but that is achieved to the extent that lifestyle considerations correlate with political perspectives.

Exposure to dissimilar views also is inhibited by the tendency for people to select politically like-minded discussion partners (Huckfeldt and Sprague 1995a). An

\footnotetext{
${ }^{1}$ Because these trends have been documented strictly for residential contexts, they do not necessarily point to greater homogeneity of political views in people's larger social network. For example, encounters in the workplace provide far more exposure to dissimilar political views than do contacts with neighbors (see, e.g., Mutz and Mondak 1998). Nonetheless, place of residence has become more of a lifestyle choice (Katznelson and Weir 1986), and increasing residential segregation has been noted according to race (Harrison and Bennett 1995), education (Frey 1995), age (Frey 1995), and income (Levy 1995).
}

ongoing obstacle to the formation of a public sphere is the persistent trade-off between amount of interaction and heterogeneity of interaction. Strong ties and frequent contact tend to characterize homogeneous interactions, which do not bring new views to one's attention (Granovetter 1973). Quantitative evidence of selective exposure in interpersonal political communication is buttressed by qualitative accounts of the courage required to speak up among heterogeneous others (e.g., Mansbridge 1980; Schudson 1984), as well as the lengths to which people sometimes go in order to avoid discussing politics (Eliasoph 1998). Selectivity appears to play a significant role in the kinds of conversations people choose to have and, thus, the kinds of political networks they form. If residential choices increasingly facilitate de facto selective exposure, and if people actively dodge any political conflict that enters their lives, then the prospects for crosscutting interpersonal interactions appear quite bleak indeed.

\section{THE MEDIA CONTRIBUTION TO CROSS-CUTTING EXPOSURE}

Few concepts have played as important a role in the history of research on mass communication as the notion that people selectively expose themselves to like-minded media content (Katz 1981). Beginning with the Erie County election study (Lazarsfeld, Berelson, and Gaudet 1944), this assumption became part of the conventional view that the media have limited effects on political attitudes (Klapper 1960). That tradition is now considered passé, but the issue of whether and to what extent people may selectively expose themselves to media content has never been fully resolved (e.g., Freedman and Sears 1965; Frey 1986; Katz 1968; Sweeney and Gruber 1984; Zillmann and Bryant 1985). Findings have been so inconsistent as to discourage much research, although studies of selective attention and bias in information processing have continued apace. Moreover, even if the many studies of selective exposure had converged on a central finding, they might not apply today, due to changes in the U.S. media environment.

Evidence of selective exposure in interpersonal relations is incontrovertible, but it is less clear with respect to the news media. Laboratory experiments that give people a choice of exposure to pro- or counterattitudinal media messages have yielded mixed results (see Frey 1986 for a review). Furthermore, such studies are very limited in what they can reveal about life outside the laboratory, where people do not always have a choice, are not always forewarned about the political content of a message before exposure, and tend to use a particular medium habitually rather than on a storyby-story basis. Particularly in light of residential balkanization, this question is worth reopening. Although the media are often criticized for presenting a very biased (e.g., Schiller 1986) or at least very narrow range of opinions and arguments on public issues (e.g., Hallin 1986), it is doubtful that interpersonal communication 
environments are any less parochial or provide greater diversity.

The idea that the media may serve as an extension of a geographically defined social context has been suggested before, but typically the emphasis is on how mass media exposure differs from face-to-face conversation (e.g., Sennett [1977] 1992). An obvious difference is the extent to which they allow interactivity. Nonetheless, if we allow that despite their noninteractive nature media may have the capacity to accomplish some of what Mill and others consider beneficial about cross-cutting communication, then exposure to dissimilar views via the media deserves attention. It is worth noting that all three of the primary benefits of exposure that Mill outlined-persuasion to a normatively better view, deeper understanding of one's own views, and the enhanced legitimacy of political decisions-are possible without face-to-face interaction. We do not mean to suggest that interactivity is of no value; rather, even without it, the media may make a significant contribution. It is possible to separate the broader issue of whether interpersonal or mass communication does more to advance the causes of democracy from the question of which kinds of channels best serve the need for exposure to cross-cutting political perspectives. We focus on this admittedly limited but nonetheless essential component of political communication.

\section{IMPLICATIONS OF AVAILABILITY AND SELECTIVITY}

We hypothesize that mainstream news media will surpass interpersonal communication in their capacity to expose people to cross-cutting political perspectives for two reasons. First, there is a greater availability of dissimilar views in Americans' media environments than in their physical environments. Second, compared to personal interactions, people have less ability and desire to exercise selective exposure to news media content. With respect to the availability of dissimilar views, the media clearly have an advantage over faceto-face communication. Mainstream reporters are generally encouraged to illustrate stories with frequent references to people or groups who express conflicting views, in the typical point-counterpoint format, and as an appeal to large audiences tend to cover a range of opinions (e.g., Zaller 1992). As businesses, American news media are certainly not insulated from pressures to reflect public opinion, but national political news in local newspapers tends not to reflect local opinion (Dalton, Beck, and Huckfeldt 1998). In other words, the news media are not subject to the more narrow geographic constraints of face-to-face relationships, and they do not reflect the structurally dictated homogeneity of immediate neighborhoods or communities.

With respect to selective exposure, it is easier to avoid exposure to the views of personal acquaintances than to views expressed in national news. With daily newspapers and most national television news, the ability to exercise choice on the basis of partisanship is severely limited. Few communities have more than one daily newspaper from which to choose; moreover, few newspapers have readily recognized political complexions that facilitate selective exposure to like-minded political views. Likewise, the political tone of national television news is very similar across channels. Of course, the same cannot be said about news magazines, talk shows, and political web sites. In more specialized media, people may well be able to select a news source that shares their political bent.

Aside from the ability to choose, media may produce less of a desire to exercise selective exposure as well. People often refrain from political discussions with heterogeneous others to avoid normative social pressure or the discomfort of public disagreement (Bennett, Fisher, and Resnick 1994; Ulbig and Funk 1999). These same people may be willing to expose themselves to media presentations, however, precisely because there is no personal interaction.

To summarize, we hypothesize that people are more likely to expose themselves to dissonant opinions through mediated rather than interpersonal communication, largely because of the lack of selective exposure involved. After describing our research design, we will evaluate contributions of the media and interpersonal communication to cross-cutting exposure and present results from three tests of our general thesis.

\section{RESEARCH DESIGN}

We used data from a representative national telephone survey sponsored by the Spencer Foundation and executed by the University of Wisconsin Survey Center in fall 1996, immediately before the presidential election. This survey included a battery of items that tapped the frequency with which respondents talked about politics with up to three political discussants, plus five separate items assessing the extent to which they agreed with the views of each discussant named (see Appendix A). These five items were combined into an additive scale that measured the extent to which people's networks expose them to political views unlike their own. ${ }^{2}$ The sample of 780 respondents provided information on more than 1,700 discussants. To obtain information about social contexts in which weak ties are especially likely, we asked respondents the same five questions with respect to people they know through work and voluntary associations, which yielded two similar indices of exposure to political difference in these contexts. Finally, the same battery was asked with reference to the views respondents encountered through reading newspapers, watching television news, reading news magazines, and watching or listening to talk shows, after initial screening for use of a particular medium. ${ }^{3}$

\footnotetext{
${ }^{2}$ Each of the five items was standardized and then combined into an additive index for each discussant and for each media source. To facilitate comparisons across information sources, they were also standardized with respect to the grand mean across all potential sources of exposure to dissimilar views. For the three primary political discussants, Cronbach's alpha indicated that these five items scaled relatively well: .78, .81 , and .81 for the first, second, and third discussant, respectively.

${ }^{3}$ Again, these items scaled acceptably: alphas of $.73, .73, .69$, and .81
} 
Although the sample is relatively small, the Spencer survey provides a great depth of information about exposure to political disagreement through both mass and interpersonal channels. Moreover, multiple indicators of the dependent variable make it possible to create indices that offer more reliable measures of the extent to which a given source provides exposure to oppositional views, as well as the extent to which it provides dissonant contact independent of the frequency of that contact.

The survey results were supplemented with data from the American and British components of the Cross-National Election Project (CNEP), obtained during the 1992 elections (for details on these studies, see Beck, Dalton, and Huckfeldt 1992; Heath et al. 1992). Although the CNEP data provide only one comparable single-item measure of the extent of exposure to disagreement through media and interpersonal channels, they allow us to replicate and extend our initial findings using data that capture both perceptions of information sources' views (those of up to five discussants, plus newspapers and television) and independent assessments of the extent of political disagreement, which were made possible by a "snowball" sample of respondents' discussants, plus a content analysis of respondents' newspapers.

Aside from the single-item (based on choice of presidential candidate) measure of political disagreement, the CNEP differs from the Spencer survey in one other respect. The CNEP asked respondents to volunteer the names of four people with whom they discussed "important matters," whereas the Spencer survey asked for people with whom they talked about "government, elections and politics." For the fifth discussant in the CNEP questionnaire, respondents were asked with whom they talked most "about the events of the recent presidential election campaign," which generated a more explicitly political discussion partner. Research on name generators suggests that the explicitly political frame will produce more nonrelatives and discussants with whom there are weak ties (Huckfeldt and Sprague 1995b). Thus, the Spencer survey is more likely to generate discussants who will be politically dissimilar to the respondent.

\section{SOURCES OF EXPOSURE TO CROSS-CUTTING POLITICAL VIEWS}

Figure 1, which is based on the combined index constructed from these five parallel measures, summarizes overall levels of exposure to dissimilar political views by mass and interpersonal information sources. Whether the items are considered separately or in summary form, the findings are highly robust. As hypothesized, mainstream news media, especially newspapers and television, occupy the highest end of the disagreement continuum, followed closely by news magazines and more distantly by talk shows. This pattern makes a great deal of sense in light of people's

for newspapers, national television news, news magazines, and talk shows, respectively. relative ability to exercise selective exposure to each of these media. It is more surprising that all the media sources, including news magazines and talk shows, surpass interpersonal sources in the extent to which respondents perceive them to involve views substantially different from their own. ${ }^{4}$

The degree of intimacy between main respondents and their discussants follows a highly predictable pattern: Closeness is inversely related to exposure to conflicting political views. Exposure to dissonant views is most likely with casual acquaintances (mean exposure to dissimilar views $=.12$ ), followed by friends $($ mean $=-.24)$, close friends $($ mean $=-1.11)$, and spouses or relatives (mean $=-1.76$ ). This significant linear trend indicates that cross-cutting exposure depends critically on contact with people who are not close friends or family $(F=18.35, p<.001)$. Moreover, as found in previous studies, the most frequent interactions tend to occur with the most politically homogeneous discussion partners (Huckfeldt and Sprague 1995a).

Even items that asked in very general terms about the people with whom respondents discuss politicsthose known through work or a voluntary association (rather than a named discussant) - did not generate levels of dissimilarity as high as those for mediated sources. These general items purposely directed respondents' attention to potentially weak ties that would have the greatest probability of putting them in contact with dissimilar views, but the responses still suggested that these sources were relatively homogeneous compared to the media. Likewise, an index of disagreement drawn strictly from nonrelative discussants confirmed that both newspapers and television expose respondents to significantly greater political disagreement than do interpersonal discussants.

The paired $t$-tests in the note to Figure 1 make it clear that these mean differences cannot be explained by political or demographic differences among the users of various information sources; in each case, the users of any two sources are compared to themselves. In all possible comparisons of media sources and discussants, the discussants were less likely to expose respondents to dissimilar political views.

Paired comparisons maximize the sample size for each of the tests, but they are inappropriate for hypothesis testing because they do not adjust the observed significance levels for the fact that so many comparisons are being made. Thus, to test our main hypothesis-that mainstream media provide more exposure to dissimilar views than face-to-face communication-we used a repeated measures analysis of variance; the

\footnotetext{
${ }^{4}$ Given the progressive decline in concord with sequentially named discussants shown in Figure 1, it is possible that a fourth, fifth, or sixth discussant would have even more heterogeneous views, but it appears that few people can name that many political discussants. In our sample only $31 \%$ of respondents named a third person. In studies that ask for five political discussants, the proportion who do not name a fourth and fifth increases sharply (e.g., Huckfeldt and Sprague 1995b), thus making it unlikely that asking about additional discussants could overcome the large difference that we have observed.
} 


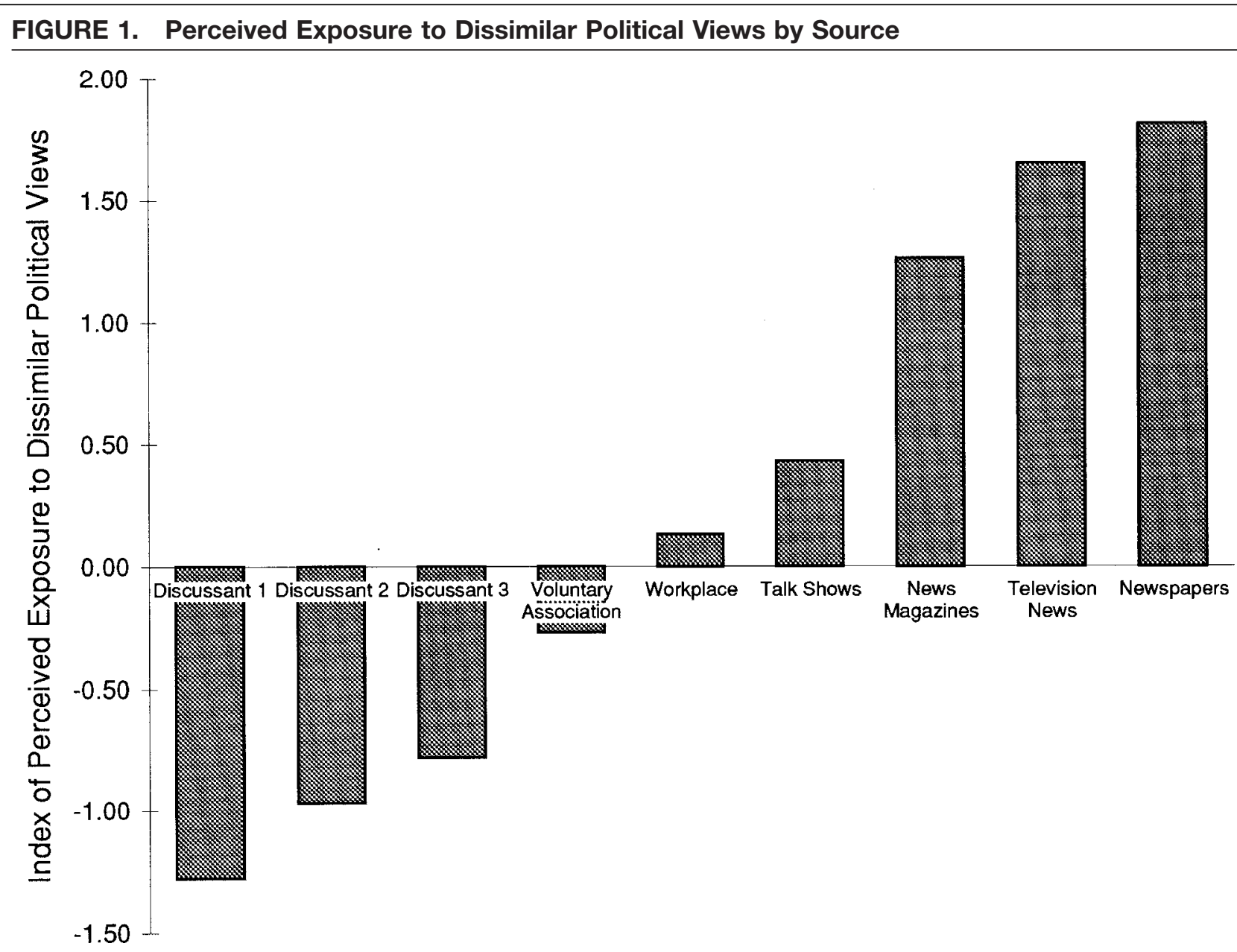

Source: Spencer survey, 1996.

Note: Sample sizes are below in parentheses, with two-tailed significance levels as noted. Statistical tests are based on pairwise comparisons.

\begin{tabular}{|c|c|c|c|c|c|c|c|c|c|}
\hline Source & (n) & $\begin{array}{c}\text { Disc. } \\
1 \\
\end{array}$ & $\begin{array}{c}\text { Disc. } \\
2 \\
\end{array}$ & $\begin{array}{c}\text { Disc. } \\
3\end{array}$ & $\begin{array}{c}\text { Vol. } \\
\text { Assn. }\end{array}$ & $\begin{array}{l}\text { Work- } \\
\text { place }\end{array}$ & $\begin{array}{c}\text { Talk } \\
\text { Shows }\end{array}$ & $\begin{array}{l}\text { News } \\
\text { Mags. }\end{array}$ & $\begin{array}{c}\text { TV } \\
\text { News } \\
\end{array}$ \\
\hline Disc. 1 & (715) & & & & & & & & \\
\hline Disc. 2 & (606) & .246 & & & & & & & \\
\hline Disc. 3 & (446) & .069 & .453 & & & & & & \\
\hline Vol. Assn. & (597) & .000 & .000 & .015 & & & & & \\
\hline Workplace & (502) & .000 & .000 & .003 & .049 & & & & \\
\hline Talk Shows & (209) & .000 & .000 & .031 & .028 & .829 & & & \\
\hline News Mags. & (151) & .000 & .000 & .000 & .001 & .002 & .246 & & \\
\hline TV News & (478) & .000 & .000 & .000 & .000 & .000 & .000 & .053 & \\
\hline Newspapers & (640) & .000 & .000 & .000 & .000 & .000 & .001 & .061 & .064 \\
\hline
\end{tabular}

information source was designated as a within-subjects factor, and simple contrasts were done between a reference condition (interpersonal exposure to crosscutting views) and mediated exposure to cross-cutting views. This procedure eliminates the problem of inflating the error rate with multiple $t$-tests, but its disadvantage when used to compare all means in Figure 1 is that the sample size for the analysis is constrained to the smallest group of media users.

In order to retain a more representative sample, we ran these comparisons for interpersonal communication versus newspaper readers and television viewers only, and we used three progressively more challenging standards for interpersonal exposure to cross-cutting views: (1) the average dissimilarity of views within the respondent's political network, (2) the dissimilarity of the third (most politically dissimilar) discussant named, and (3) the dissimilarity of views among coworkers. The omnibus $F$ tests for all three analyses were highly significant $(F=214.35,54.77$, and 40.39 , respectively, $p<.001$ in all cases), as were the individual contrasts between interpersonal exposure versus television news $(F=263.30,69.21$, and 39.84 , respectively, $p<.001$ in all cases) and interpersonal exposure versus newspaper news $(F=301.65,71.35$, and 66.02 , respectively, $p<.001$ in all cases). Finally, we also included income, education, political interest, and partisanship in those models to see whether the gap 


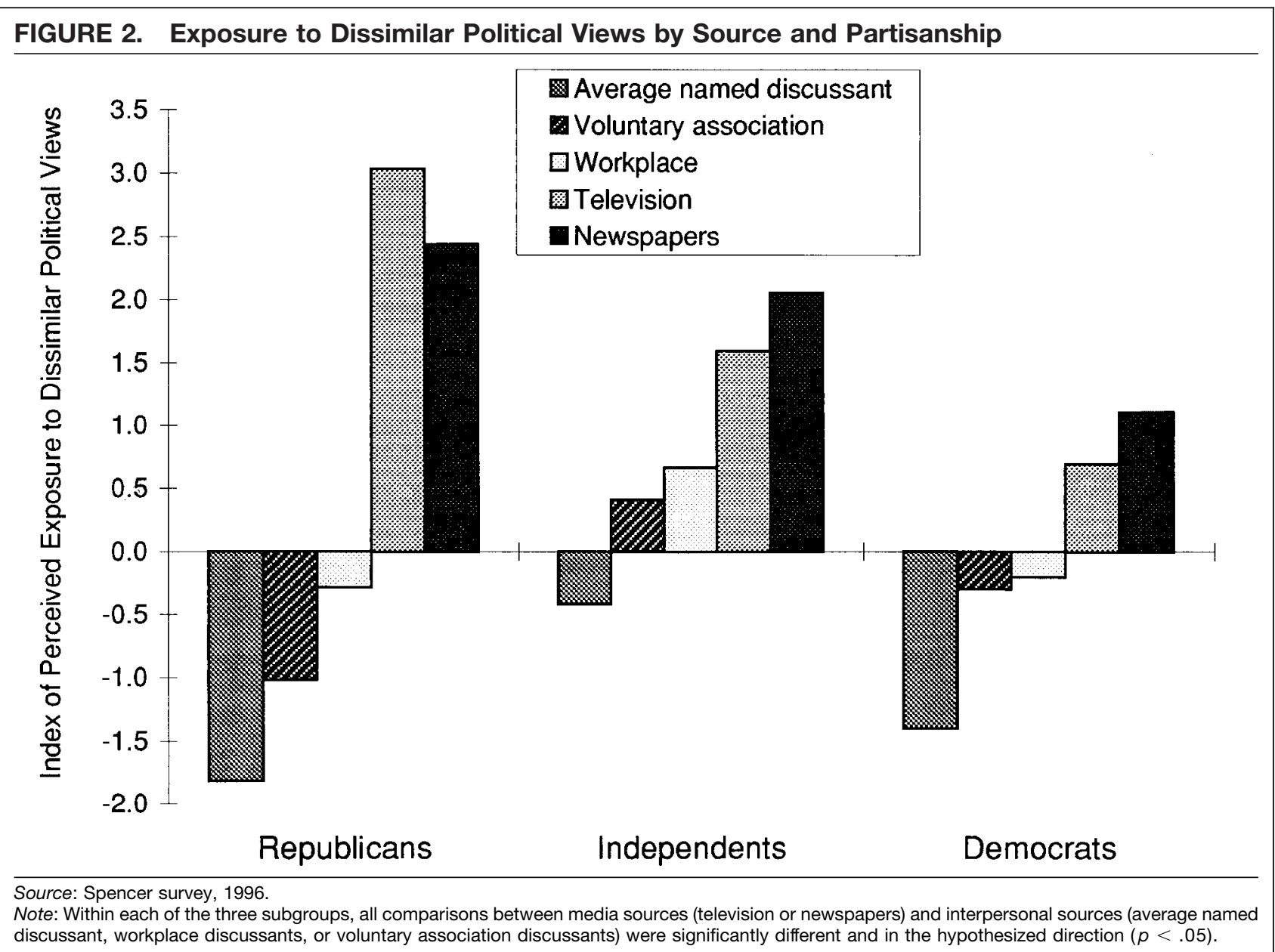

was especially pronounced in particular subsets of the population. The observed gap persisted in all cases, although partisanship was a particularly influential covariate.

As Figure 2 illustrates, there are important differences by party: Democrats tend to find mainstream news sources more agreeable, whereas Republicans have significantly more homogeneous interpersonal networks. These two tendencies combine to increase the size of the gap between media and interpersonal exposure to dissimilar views among Republicans, but it is both sizable and statistically significant among Democrats and independents as well. ${ }^{5}$ In other words, the fundamental advantage of media in exposing people to dissonant information transcends partisanship.

The differences between extent of exposure to political dissonance through mainstream news media and through interpersonal networks are clearly large, robust, and statistically significant, but one might question whether the pattern observed in these data is

\footnotetext{
${ }^{5}$ A repeated measures analysis of variance strictly among Democrats that simultaneously compared the interpersonal discussant average with exposure to difference through television and newspapers produced very strong findings (omnibus $F=51.68$; contrast between personal network and TV: $F=62.39$; contrast between personal network and newspapers: $F=77.06$; all $p<.001$ ).
}

"real" or largely perceptual. 6 Unlike snowball samples, which ask named discussants about their political views, or content analyses of media messages, our measures examined thus far do not tap the actual similarity or dissimilarity of views but respondents' perceptions. These perceptions are subject to distor-

\footnotetext{
${ }^{6}$ Another possible challenge to our interpretation is that, for people whose views are outside the mainstream, measures of disagreement constructed from party or candidate preference questions may not adequately operationalize exposure to disagreement. Many critics of the press highlight not so much an imbalance in presenting mainstream Republican or Democratic views as a dearth of more radical perspectives on either side of the spectrum. It should be noted, however, that three items in the index make no reference to parties or candidates, and the pattern of findings is virtually identical using an index comprised of only these three items. Thus, we do not believe that the components of the index addressing only mainstream political views account for the findings.

It is also possible that, even though the indices are comprised of identical items for media and interpersonal communication, a word such as "often" means something very different when applied to media versus interpersonal political communication (Schaeffer 1991). Relative frequency is involved in only one of the five items in the index. In addition, this argument should work against our hypothesis, because phrases indicating relative frequency will tend to mean larger absolute frequencies when the activity is more frequent, and interpersonal exposure to political news is less frequent than mediated exposure.
} 


\section{TABLE 1. Accuracy of Respondent Perceptions}

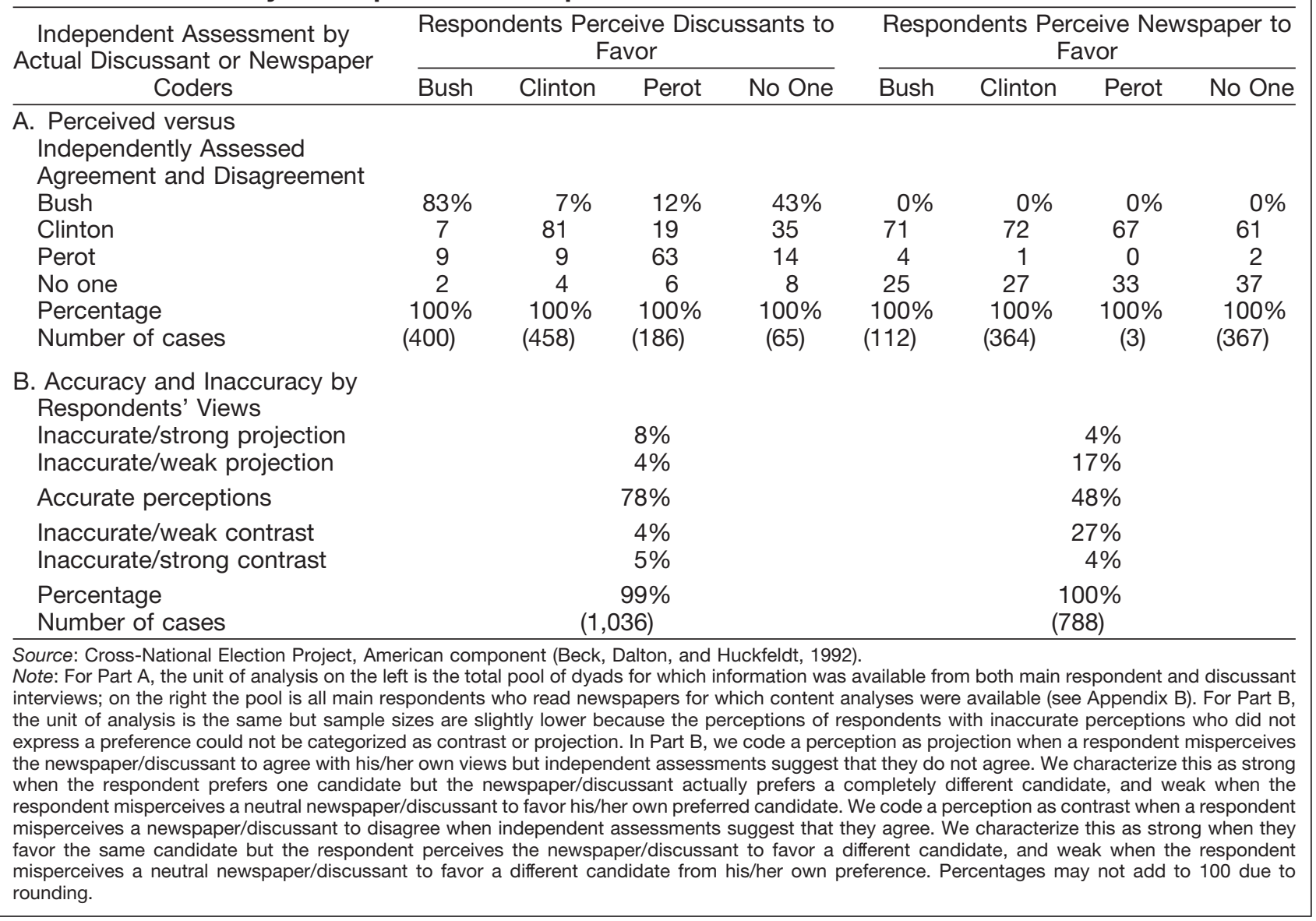

tion and inaccuracy; for example, a great deal of interpersonal disagreement goes unrecognized, and errors sometimes occur in recognizing agreement as well (Huckfeldt et al. 1995).

For our purposes, we consider perceptual measures of disagreement more appropriate than actual measures. In order for disagreement to stimulate the kind of thought processes and reevaluation cited by Mill and others, it must be perceived as such. If people so misperceive others' views as to consider them to be in agreement, then they will not be prompted to reconsider their opinions, broaden their perspectives, and so forth. Likewise, if people perceive that others disagree-even if this is not the case-then the same benefits may derive despite the lack of objective disagreement. Thus, in one important sense, it may be meaningless to ask whether people are "really" exposed to views different from their own. If discussants are hesitant to make their difference of opinion known to friends, or if people persistently ignore differences that are communicated to them, then such interactions contribute little to the kinds of benefits political theorists have proposed. Moreover, Huckfeldt and Sprague (1995a) found that respondents were influenced exclusively by the views they perceived their discussants to have, not by their actual views.

Nevertheless, have we observed anything more than a conglomeration of systematic perceptual distortions?
The question is important because research in two areas highlights the systematic distortion in the perceptions of others' views that can result from strong partisan leanings. False consensus studies suggest that people will overestimate the extent of their agreement with others, and studies of the hostile media phenomenon indicate that people sometimes overestimate the extent of their true disagreement with the mass media (Giner-Sorolla and Chaiken 1994; Vallone, Ross, and Lepper 1985). Separately or in combination, these perceptual distortions may account for our finding of greater exposure to perceived political disagreement through the mass media than through interpersonal communication.

Drawing on the CNEP data, Table 1 shows that most perceptions of interpersonal agreement are accurate; overall, for all respondent-discussant dyads, respondents correctly named the political views of over $70 \%$ of their discussants. We sorted based on whether the distortion was in the direction of the main respondent's view (projection) or away from it (contrast). We then classified these cases as strong, if the misperception was the opposite of the discussant's true preference, or weak, for example, when a true independent or undecided discussant was perceived as a Democrat by a Democratic respondent.

As the bottom left panel of Table 1B shows, roughly $12 \%$ of respondents erred in the direction of their own 


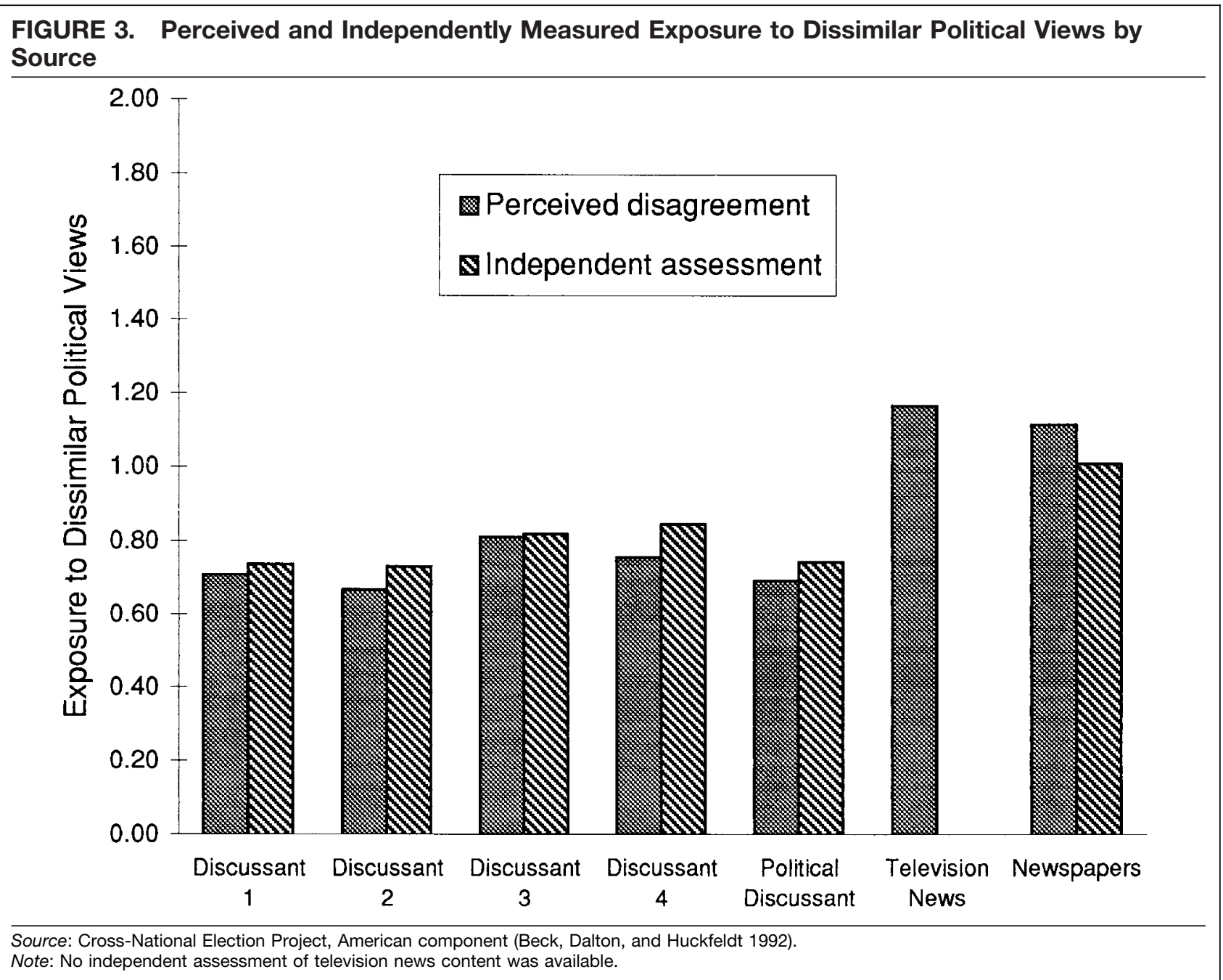

views, and $9 \%$ in the direction opposite their own views. The results suggest significant projection $(t=$ $2.72, p<.01)$, consistent with much of the psychological literature on this topic (e.g., Fabrigar and Krosnick 1995; Krueger and Clement 1994). ${ }^{7}$ In other words, systematically more errors occurred in the direction of perceiving greater interpersonal agreement (projection) than was actually the case, just as the false consensus hypothesis predicts. The bottom line is that people are exposed to more interpersonal disagreement than they recognize, but because they fail to recognize it, it probably has little capacity to produce the beneficial effects of cross-cutting exposure. Conversely, as shown in Table 1A for newspapers, there is a tendency to perceive greater disagreement (contrast) with the media than content analyses suggests to be the case. ${ }^{8}$ For newspapers, $21 \%$ of respondents showed signs of projection, and a significantly greater $31 \%$ showed signs of contrast $(t=3.56, p<.001)$.

\footnotetext{
7 To test whether the errors were random or systematically in the direction of respondents' own views, we assigned values of -2 to +2 to the contrast and projection scores, with accurate perceptions equal to 0 . We then tested the hypothesis that the mean was equal to 0 . ${ }^{8}$ We use newspapers for this comparison because content analysis is available.
}

In Figure 3, the CNEP U.S. data seem to confirm the pattern observed in the Spencer survey, in that people perceive media to expose them to more oppositional views than do their personal networks. As shown by the solid bars, this is true across the four "important matters" discussants as well as for the explicitly "political" discussant. The striped bars in Figure 3 represent independent assessments provided by discussants and drawn from independent coding of respondents' newspapers. ${ }^{9}$ Figure 3 suggests that the true extent of exposure to oppositional views may be slightly overestimated in the case of newspapers and somewhat underestimated in the case of interpersonal relations. But most important, even if one uses the "real" measures based on discussant reports and content analyses, newspapers still provide significantly greater exposure to views different from the respondents' own $(t=5.74$, $p<.001)$. In other words, the advantage of news media over interpersonal channels in relaying political

\footnotetext{
${ }^{9}$ Whether a publication favored one candidate or none was established by running a repeated-measures analysis of variance on the articles coded for each newspaper to see whether there was a statistically significant difference in favorability and, if so, in what direction. If no statistically significant difference emerged, the newspaper was coded as favoring no one.
} 
disagreement is real, not simply a matter of perceptual distortion.

Although the Spencer data do not include independent measures of exposure to disagreement by source, the results are consistent with the CNEP finding that the relative media advantage is not simply a function of perceptual distortion. The perceptual distortion inherent in both false consensus and hostile media effects is driven by partisanship; in the former case, it leads people to perceive greater support for their own views than truly exists in their environment, and in the latter case, it leads them to perceive greater opposition. Another way to grasp the extent of partisan distortion in the perceptual data is to examine whether the same relative advantage of news media over interpersonal sources exists among political moderates or nonpartisans. ${ }^{10}$ Figure 2 illustrated that even independents (or those without ideological leanings), that is, people with little or no partisan predisposition to distort their impressions of conflict and consensus, believe the news media expose them to dissimilar political views more than interpersonal sources (newspapers: $t=6.97, p<$ .001 ; television: $t=6.61, p<.001)$.

Figure 4 makes an additional point concerning the relationship between partisan extremity and exposure to cross-cutting political perspectives. If we were to plot the hostile media hypothesis on one of these graphs it would be U-shaped; studies demonstrating a hostile media effect show that partisans at either end of the spectrum will report more exposure to oppositional views, even when the exact same media content is involved (Vallone, Rose, and Lepper 1985). If a medium were instead perceived to be more congenial to one side of the political spectrum than the other, we would expect a linear pattern: People at one end of the spectrum would find it least dissimilar to their own views, people at the other end would consider it dissimilar, and most independents and nonpartisans would fall somewhere between.

Figure 4 plots all the available indices of exposure to disagreement, for both mediated and interpersonal channels, across levels of partisanship. In addition to showing the means for each level of partisanship, it reveals either linear or curvilinear patterns depending on whether trend tests across the means indicated a significant linear or curvilinear component, with the highest order significant pattern displayed. In the top panel of Figure 4, for all media sources there is a significant linear pattern; compared to Democrats, Republicans perceive television and newspaper news as exposing them to a great many more views unlike their own. For talk radio, the pattern is reversed but still linear: Democrats are more likely than Republicans to find that the views expressed are in disagreement with their own, and independents fall in the middle. Despite the relative consonance of views that Republicans perceive in talk shows, they believe this medium offers

\footnotetext{
${ }^{10}$ Independents and those who refuse to identify themselves in partisan terms may be quite different, but examination of these groups separately and collectively produced the same pattern of results.
}

dissimilar views to a greater extent than do their interpersonal networks (repeated-measures analysis for television versus personal network average among Republicans, $t=2.44, p<.05$ ).

Although the earlier finding of greater contrast than projection in perceptions of newspaper content seemed consistent with the hostile media hypothesis, Figure 4 makes the further point that it would be erroneous to describe this pattern as one in which partisans on both ends of the political spectrum see the news media as more hostile to their views than do independents (cf. Dalton, Beck, and Huckfeldt 1998).${ }^{11}$ Democrats perceive newspapers and television news to be relatively agreeable but, as shown in Figure 2, Democrats still consider these sources more dissonant than their interpersonal networks.

As shown in the bottom panel of Figure 4, in contrast to the linear patterns for media, interpersonal assessments of exposure to dissimilar views consistently yield an inverted U-shape. This indicates that, as compared to independents, strong partisans are less exposed to views unlike their own. The pattern holds for both the index for average discussants and contacts in the workplace or through voluntary associations.

If people successfully exercise selective exposure, then one would expect to see a pattern in which strong partisans are most likely to be exposed to consonant information, and weaker or nonpartisans less so. Indeed, the fact that this pattern is true for interpersonal sources but not for mainstream media lends support to our argument that selective exposure is less influential in shaping people's exposure to mediated than to interpersonal information. There are, of course, other differences between strong and weak partisans, but it is worth noting that the generally narrower latitudes of acceptance of the strongly partisan should work against this finding; strong partisans should find more views expressed by media and by other people disagreeable if only because not much of a difference of opinion is required for strong partisans to perceive a viewpoint as unlike their own (e.g., Sherif and Hovland 1961).

Findings from the CNEP replicate these patterns. For television news and newspapers, perceived disagreement is a linear function of partisanship. For interpersonal communication, strong partisans on both sides of the political spectrum are exposed to less disagreement than independents. Moreover, this pattern remains curvilinear whether based on respondents' perceptions or the independent reports of discussants.

In sum, our evidence suggests that most people perceive substantial political harmony in their interpersonal associations and tend to misperceive disagree-

\footnotetext{
${ }^{11}$ We use the same data as these authors for much of our analyses, but we arrive at different conclusions about a hostile media effect because the single variable for partisanship (ranging from strong Democrat to strong Republican) on which they base their interpretation cannot distinguish between a hostile media pattern and the partisan media perception we observe, i.e., only Republicans (but not Democrats) perceive media coverage as more hostile to their views (see Giner-Sorolla and Chaiken 1994; Vallone, Ross, and Lepper 1985).
} 


\section{FIGURE 4. Perceived Dissimilarity of Views by Source and Strength of Partisanship}
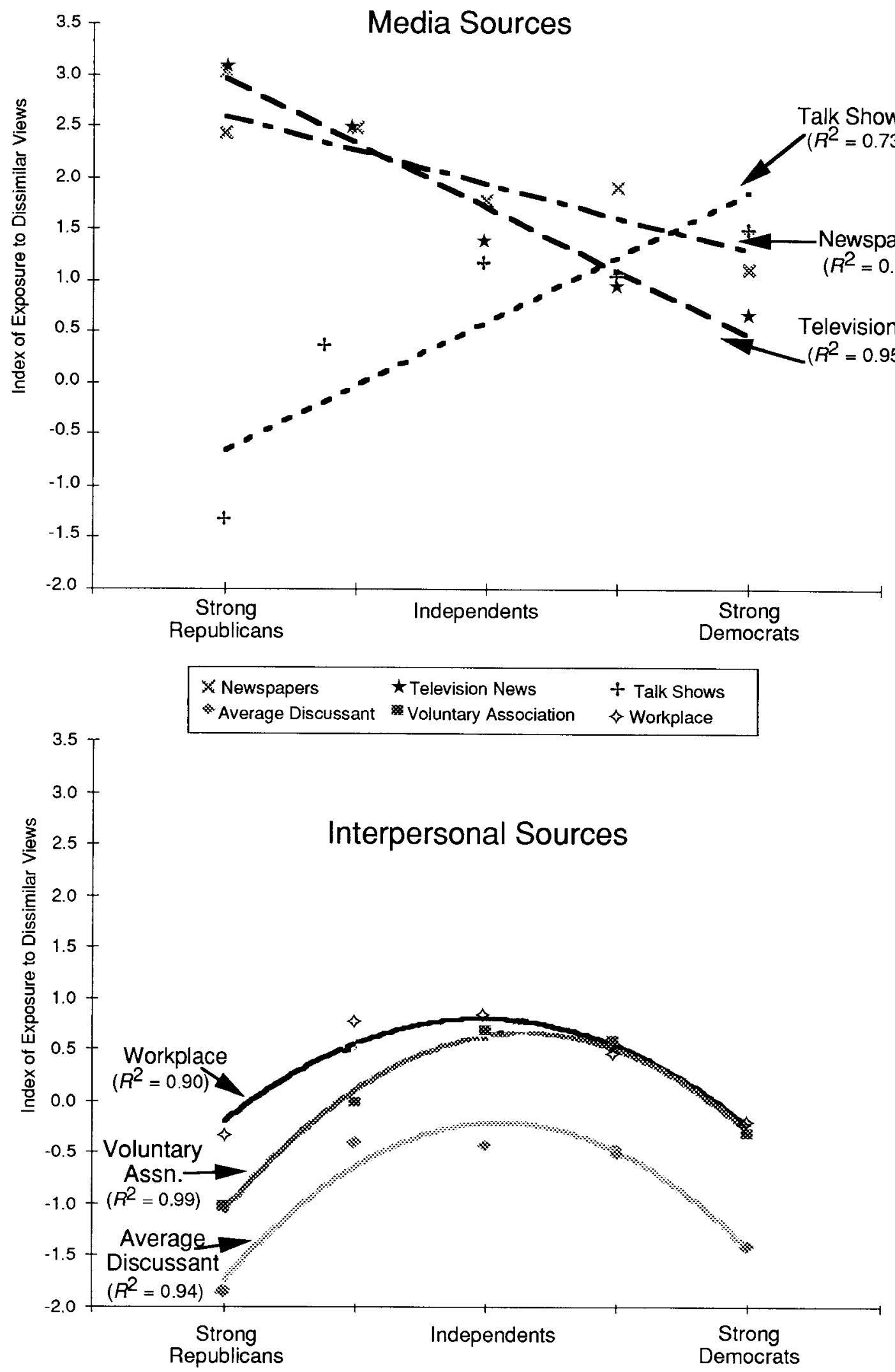
ment that may exist. Political diversity is clearly not a goal in social relationships for most Americans; people tend to cultivate homogeneous interpersonal networks, and those with strong partisan attitudes are particularly likely to be surrounded by similar others. In comparison, the mainstream media expose people to more political disagreement, regardless of partisanship or the exremity of their views.

\section{EXPLAINING THE MEDIA ADVANTAGE}

What is it about media that enables these communication channels to more successfully expose people to cross-cutting political viewpoints? We suggest that people often seek political reinforcement from their information sources, whether mass or interpersonal, but that the extent to which people are exposed to dissimilar views through a given source reflects variation in their motivations to exercise selective exposure and the ease with which it is possible to do so. This hypothesis can be tested in three different ways with the Spencer data. First, choice should facilitate less exposure to dissonant views. Therefore, one would expect people with a choice of local daily newspaper to agree more with the views in the one selected than do those with no choice.

Second, our theory also implies that findings should depend upon the media culture of a particular time and place. One would expect, for example, that our findings would be time-bound even in the United States; in the era of the partisan press it is unlikely that people received much except partisan reinforcement from their daily papers (Schudson 1981). Newspapers of that period would not have fared any better than face-toface communication in exposing people to cross-cutting views. While we have no suitable historical data to test this hypothesis, we can approximate such a comparison by comparing the contemporary United States to a country where the press is more closely aligned with parties and political views. Drawing on the British component of the CNEP, we compare exposure to cross-cutting views in American and British newspapers and interpersonal networks. We expect that selective exposure is much easier when the media are overtly partisan, and British newspapers should play a less important role than the American press in exposing people to dissimilar political views.

Third, we examine individual differences in the extent to which people are comfortable with face-to-face conflict and thus are differentially motivated to exercise selective exposure. Although people in general dislike conflict, there are individual variations in how strongly people are motivated to avoid it (Ulbig and Funk 1999). We hypothesize that the media will be responsible for a particularly large proportion of a person's total exposure to dissonant views if he or she is uncomfortable with face-to-face disagreement.

\begin{tabular}{|c|c|c|}
\hline & $\begin{array}{l}\text { Coefficient } \\
\text { (s.e.) }\end{array}$ & $t$-value \\
\hline $\begin{array}{l}\text { More than one newspaper } \\
\text { available in area }\end{array}$ & $-.43^{\star}(.20)$ & 2.20 \\
\hline $\begin{array}{l}\text { Republican Party } \\
\text { identification }\end{array}$ & $-.07 \quad(.22)$ & .30 \\
\hline $\begin{array}{l}\text { Democratic Party } \\
\text { identification }\end{array}$ & $-.72^{\star \star}(.22)$ & 3.25 \\
\hline Education & $-.01 \quad(.04)$ & .26 \\
\hline Age & $.00 \quad(.01)$ & .49 \\
\hline Sex & $-.25 \quad(.19)$ & 1.34 \\
\hline Race & $.37 \quad(.28)$ & 1.34 \\
\hline Income & $.01 \quad(.01)$ & 1.80 \\
\hline Constant & $1.56^{\star}(.71)$ & 2.19 \\
\hline $\begin{array}{l}R^{2} \\
(n)\end{array}$ & $\begin{array}{c}.06 \\
(460)\end{array}$ & \\
\hline
\end{tabular}

Source: Spencer survey, 1996.

Note: Availability is coded 1 for zip code areas with only one newspaper, 2 for areas with more than one. Entries are ordinary least-squares regression coefficients, with standard errors in parentheses. ${ }^{*} p<.05$, ${ }^{* *} p<.01$.

\section{Local News Options}

If the motivation to selectively expose one's self influences political information consumption (despite the difficulty in fully realizing this goal), then those who live in areas with a choice of local daily newspapers should be exposed to fewer dissonant views in the one they choose. Of course, the difference in political slant between local newspapers can be very subtle, but nonetheless the population in multiple newspaper towns has some degree of choice. To test our hypothesis, respondents in the Spencer survey were matched with information about the circulation of daily newspapers in their zip code area, as obtained from the Audit Bureau of Circulation. Zip code areas with only one daily were coded 1 ; those with more than one were coded 2. Because correlates such as income, education, or partisanship might produce a spurious relationship or mask a significant relationship between exposure to dissimilar views and access to multiple newspapers, control variables were included. For example, markets with multiple newspapers are likely to be better educated and urban, and these demographic characteristics may be associated with the likelihood of exposure to diverse viewpoints.

As shown in Table 2, respondents in areas with more than one newspaper reported significantly less exposure to dissimilar views through their daily newspaper, even after controlling for partisanship and other variables, although the model as a whole accounts for very little variance in exposure to disagreement. Given the often subtle differences in the political complexion of newspapers within a locale, the modest size of the effect is not surprising. 


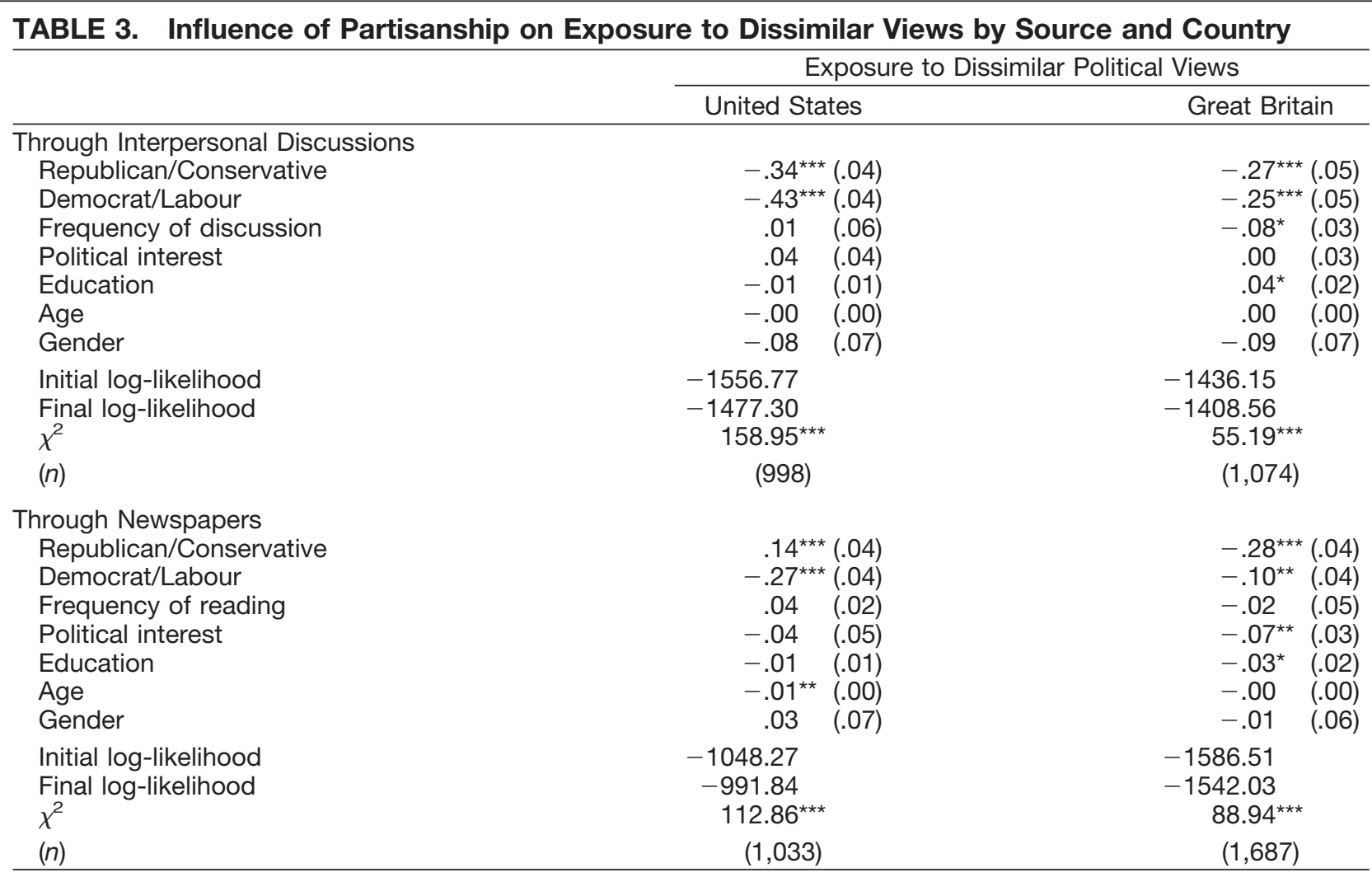

Source: Cross-National Election Project, British and American components, 1992.

Note: For interpersonal discussion, the dependent variable is the average exposure to dissimilar views through all the respondent's discussants; for newspapers, it is the extent of exposure to dissimilar political views through the respondent's most often read newspaper on the same scale. Entries are ordered probit coefficients, with standard errors in parentheses. Cutpoints are not shown. ${ }^{*} p<.05,{ }^{* \star} p<.01,{ }^{\star \star \star} p<.001$.

\section{A Partisan Media Environment}

A media environment with more sharply defined political differences between newspapers provides a better test of whether selective exposure is exercised when conditions make it easier to do so. British voters are well aware of the partisan slant in their newspapers, and there are many competing products from which they can choose (Curtice, Schmitt-Beck, and Schrott 1998, 12). If we are correct that the largely nonpartisan U.S. press makes it difficult for people to selectively expose themselves to media content, then we would expect a markedly different pattern among British respondents. Because British partisans should find it relatively easy to exercise selective exposure, the relationship between partisanship and exposure to dissimilar views should take the same curvilinear shape as for interpersonal sources, that is, strong partisans on both sides should be less exposed to dissimilar political views.

Table 3 examines the relationship between strength of partisanship and exposure to dissimilar views through the media and interpersonal communication for British and American respondents. In the top panel we find in both samples the same pattern shown in Figure 4 for interpersonal discussants in the Spencer survey. As the significantly negative coefficients in the top two rows of Table 3 indicate, partisanship in both countries reduces the amount of cross-cutting interpersonal exposure that people experience. In the bottom panel, the hypothesized difference between the amount of selective exposure exercised in the two news environments is confirmed. As anticipated, British partisans on both sides are significantly less likely than Americans to be exposed in their newspapers to political views with which they disagree. In other words, they can and do find news sources that mesh with their political predispositions. Just as with face-to-face exposure, strong partisanship in Britain promotes greater selective exposure.

In contrast, the American case reveals a simple linear pattern: compared to nonpartisans, Democrats are less likely to encounter dissimilar views in their newspapers than are nonpartisans, but Republicans are more likely than are nonpartisans to do so. To confirm a general pattern of selective exposure, both party coefficients need to be significant and negative, but the coefficient for Republicans is significant and positive. In other words, given the opportunity to exercise selective exposure through their choice of newspaper, respondents could do so in the highly partisan British news environment, but fewer could do so in the American case. The differing results can be seen in the marginals for these dependent variables as well. Among newspaper readers, 51\% in Britain read a paper that shares their political leanings, but in the United States the figure is only $16 \%$. Conversely, $35 \%$ in the United States read a paper that explicitly disagrees with their political leanings, whereas the com- 
parable figure in Britain is only $20 \%$. In both countries there is more cross-cutting exposure through newspapers than through interpersonal networks, but the difference between the extent to which newspapers and interpersonal communication provide exposure to dissimilar views is significantly larger for Americans $(t=$ $4.58, p<.001)$. Selective exposure clearly occurs under the right real world conditions; when people have a choice, they tend to use it to reduce their exposure to cross-cutting political views.

\section{Comfort with Face-to-Face Controversy}

In addition to limited opportunities to exercise selective exposure, the media advantage over interpersonal sources may be due to its impersonal nature, which circumvents the discomfort of face-to-face controversy. Beyond fewer opportunities to exercise selective exposure, Americans may have less motivation to do so with mass media. We hypothesize that people will obtain a larger relative proportion of their total exposure to dissimilar views from interpersonal communication if they are comfortable with face-to-face conflict. As a test we used two survey items designed to assess the communication patterns encouraged during early political socialization in the family (see Appendix A for question wording and McLeod and Chaffee 1972 for a review of the literature). For our purposes, it matters little whether these items tap accurate recollections of parental behavior or reflect current attitudes toward controversy. In either case, we anticipate that people who are uncomfortable with face-to-face conflict are likely to get more of their dissonant information from the media relative to people who are comfortable with interpersonal conflict.

We compared the average level of exposure to disagreement in respondents' interpersonal networks with the average level for television and newspapers, subtracting the former from the latter. A high score on this measure indicates greater media exposure to dissonance, and a low score indicates greater interpersonal exposure. Because these difference measures are not independent of overall exposure levels, we included a control for the total amount, that is, the sum of media and interpersonal exposure. This allowed us to estimate the relative importance of the media, controlling for the effect of overall exposure levels. Due to the obvious role of general political interest in motivating exposure, it was also included.

As shown in Table 4, the total amount of exposure to dissimilar views positively predicts the importance of media relative to interpersonal sources. The relative importance of media is especially great for Republicans, who have significantly more homogeneous interpersonal networks than Democrats. In contrast, a high level of education makes the media less important vis-à-vis interpersonal sources. Most important for our hypothesis about why people turn to the media is the controversy scale, which is a significant negative predictor of the relative importance of the media. In other words, as expected, people who are comfortable with face-to-face conflict get a relatively larger amount of

\begin{tabular}{|c|c|c|}
\hline & $\begin{array}{l}\text { Coefficient } \\
\text { (s.e.) }\end{array}$ & $t$-value \\
\hline $\begin{array}{l}\text { Comfort with face-to-face } \\
\text { controversy }\end{array}$ & $-.37^{\star} \quad(.16)$ & 2.35 \\
\hline $\begin{array}{l}\text { Total exposure to } \\
\text { dissimilar views (media } \\
\text { average }+ \\
\text { interpersonal average) }\end{array}$ & & \\
\hline $\begin{array}{l}\text { Interpersonal average) } \\
\text { Political interest (high) }\end{array}$ & $\begin{array}{ll}.47^{7 \star x} & (.05) \\
.35 & (.34)\end{array}$ & $\begin{array}{l}9.21 \\
1.02\end{array}$ \\
\hline Republican Party & & \\
\hline $\begin{array}{l}\text { identification } \\
\text { Democratic Party }\end{array}$ & $3.74^{\star \star \star}(.70)$ & 5.33 \\
\hline identification & $.58 \quad(.66)$ & .89 \\
\hline Education & $-.26^{\star} \quad(.13)$ & 2.06 \\
\hline Age & $.01 \quad(.02)$ & .40 \\
\hline Income & $.01^{*} \quad(.00)$ & 2.30 \\
\hline Race & $-.65 \quad(.82)$ & .79 \\
\hline Gender & -.67 & 1.19 \\
\hline Constant & $5.59^{\star} \quad(2.36)$ & 2.37 \\
\hline $\begin{array}{l}R^{2} \\
(n)\end{array}$ & .38 & \\
\hline
\end{tabular}

Source: Spencer survey, 1996.

Note: The dependent variable is the relative importance of the media (averaged level) compared to interpersonal network (averaged level). Entries are ordinary least-squares regression coefficients, with standard errors in parentheses. ${ }^{*} p<.05,{ }^{* \star *} p<.001$.

their dissonant information interpersonally rather than from the media. The opposite is true for people who find controversy unpleasant; they are more likely to be exposed to dissimilar views through the media. This finding supports our proposition that impersonality helps explain the media advantage. Variability in selective exposure reflects not only the availability of partisan information sources, as shown in tables 2 and 3 , but also individual differences in the desire to avoid interpersonal conflict.

\section{DISCUSSION}

Communication across lines of political difference is essential to the social psychological basis of a pluralist society. Pluralism requires that a society be able to endure ongoing political and moral disagreement (e.g., Berlin 1969). Furthermore, according to most democratic theorists, the expression of opposing political views is integral to the democratic process. Yet, the desire for harmony in interpersonal relationships makes political disagreement both relatively infrequent and particularly difficult to convey successfully. In addition, residential balkanization in the United States is decreasing the likelihood of heterogeneous face-toface interaction. These factors make it all the more important to understand the avenues through which people obtain exposure to dissimilar political views. Our findings suggest that media are far more important than interpersonal networks in exposing people to views unlike their own. As a result, the media have the potential to make an extremely important contribution 
to awareness of diverse political perspectives and thus to national political integration. ${ }^{12}$

Our findings also have implications for many debates regarding the media and public opinion in the United States. On the one hand, the stereotypes that Lippmann (1922) feared capable of eliminating exposure to dissonant viewpoints altogether appear to be potent but limited forces. Selective exposure is exercised with respect to interpersonal contacts in the contemporary United States, to be sure, but at least as of the 1990s, the structure of mainstream media makes it difficult for people to screen out large amounts of oppositional information. On the other hand, cross-cutting exposure and intrapersonal awareness of oppositional views does not necessarily translate into the kind of face-to-face deliberation that theorists such as Dewey (1927) had in mind. Nonetheless, traditional news media such as newspapers and television news hold the potential for creating greater awareness of cross-cutting views.

Many theorists, like Dewey, have suggested that only face-to-face deliberation can bring about the kind of democratic ends implied by the notion of a public sphere (e.g., Barber 1984; Fishkin 1991). Others emphasize that, "in modern societies, public deliberation is (and probably must be) largely mediated" (Page 1996). The usual rationale is that the mass media may be fine for relaying information, but they are not very useful for fostering public discourse and collective action, because they are essentially one-way communication to people in spatially dispersed and privatized settings (Carey 1987). ${ }^{13}$ This argument makes considerable sense if collective action or consensus-building is the outcome of interest. But if one focuses instead on the importance of exposure to political perspectives in order to promote awareness of diverse viewpoints, political tolerance, and benefits of this kind, then the inherent limitations on the media's contributions are less obvious.

The sheer idea that mass media might serve to the benefit of the public sphere strikes most as heretical. But, in assessing media's contribution, there is a tendency to rely on an ideal standard drawn from interpersonal communication, typically akin to the ideal

\footnotetext{
12 Our findings are consistent across two data sets and two presidential elections, but this could be a function of similarities between the 1992 and 1996 elections. For example, the perception among Republicans and Democrats of media favoritism toward Clinton may be a function of his front-runner status in both cases. Nonetheless, our findings are consistent with many previous studies in suggesting that Americans perceive media content as to the left of their positions and consider journalists more liberal than the general population (Weaver and Wilhoit 1996). This does not necessarily mean that the content journalists produce favors one side, but the perception is that the mainstream media lean left if they lean at all (Watts et al.).

${ }^{13}$ Much has been made of the importance of direct interpersonal relationships in nurturing a sphere of politically oriented discourse, but a growing number of perspectives challenge that idea. Sanders (1997), for example, points out that the formal standards for the deliberative ideal are seldom, if ever, met. As usually practiced, face-to-face deliberative decision making may essentially perpetuate and exacerbate social inequalities. Schudson (1997) disputes the conversational ideal that pervades current writing on the quality of public life, arguing that democracy has little to do with the kind of intimacy and community that characterize this romanticized view of face-to-face interaction.
}

speech situation (Habermas 1989) in which everyone has an equal opportunity to participate, everyone listens to and carefully considers others' views, and so forth (e.g., Fishkin 1991; Knight and Johnson 1994). This "conversational ideal" is not drawn from realworld experience, but it is often used as the standard against which media are judged and found wanting: "We are not really interested in what face-to-face communication is like: rather, we have developed a notion that all communication should be like a certain model of conversation, whether that model really exists or not" (Schudson 1982, 43, emphasis in original).

Instead, if we compare the reality of face-to-face political communication with the reality of media political communication, we have a more solid foundation on which to base conclusions about the contributions that both forms may make to a public sphere. There is a disappointing tendency toward homogeneity in faceto-face political communication, whereas the media can transcend interpersonal geography and expose people to views unlike their own. Regardless of one's views on whether the media present a broad enough range of perspectives, it is clear that for many Americans they are the main source of exposure to crosscutting political views. Compared to most interpersonal networks, they are hotbeds of diversity, not because the media are doing such an exemplary job pursuing diversity, but because individuals are doing such a poor one, in part because of the desire to avoid conflict in interpersonal situations. The media send multiple conflicting messages, and in so doing they advance an important aspect of the democratic process.

Of course, the patterns we have observed could simply be interpreted as evidence of the media's limited influence on political attitudes. That is, if homogeneous interpersonal channels persuade people to hold certain views, and the media are not equally persuasive, then the media will, as a result, appear to provide more exposure to dissimilar views. Even if this were the case, it still could be argued that media play an important role in furthering cross-cutting exposure in a way that interpersonal communication does not and perhaps cannot. Previous studies have found limited support for the social cohesion view of the effect of political discussants (cf. Huckfeldt and Sprague 1995a; Kenny 1994), that is, that the cohesiveness of social relationships determines their persuasiveness. But regardless of the relative power one attributes to mass or interpersonal communication to persuade people to change their mind, any exposure to differing views that does not produce instantaneous compliance is a valuable component of public opinion formation and of the process of legitimizing differing views within a pluralist system.

In the contemporary United States, the major problem with looking to media to fulfill this role is the current trend toward highly specialized rather than mass channels. The breakup of the network broadcast monopoly, the proliferation of Internet news sources, and the potential they offer for tailoring news to one's own interests and prejudices are only a few signs of this 
trend. As the number of potential news sources multiplies, consumers must choose among them, and that exercise of choice may lead to less diversity of political exposure. Although media observers have long lamented the lack of choice in news sources, the proliferation of choice creates new problems. Advertisers and media firms are now working together to create "electronic equivalents of gated communities" (Turow 1997, 2). The market segments they identify often are not based explicitly on political views, but "lifestyle" categories are hardly independent of political leanings.

Turow $(1997,3)$ argues that "segment-making media," those which "encourage small slices of society to talk to themselves," are on the rise, whereas "societymaking media," which "have the potential to get all those segments to talk to each other," are on the decline. This leaves the future of the mass audience in question (cf. Neuman 1991). These developments obviously do not bode well for the future of communication across lines of political difference. In addition to reducing the amount of direct exposure to dissonant views, specialized media and fragmented audiences may have secondary negative effects on interpersonal communication, since shared viewing or reading may encourage conversations across partisan lines (Katz 1996).

Ironically, the mass media's greatest strength may not be facilitation of the "Great Community" of solidarity envisioned in the early twentieth century by media philosophers such as Cooley and Dewey (Simonson 1996). Instead, media's greatest potential lies in its impersonal exposure of audiences to cross-cutting views, an essential form of communication in a highly pluralistic society. In order to sustain this benefit, however, news media must be structured so as to limit the public's capacity for selective exposure.

\section{APPENDIX A. THE SPENCER SURVEY}

\section{Design}

This national telephone survey was conducted by the University of Wisconsin Survey Center from September 1996 through election eve using random digit dialing. Each number was screened to verify that it was associated with a household. The person selected for the interview was randomly chosen from among household members at least 18 years old, with no substitutions allowed. The response rate was $47 \%$, calculated as the proportion of completed interviews divided by total sample (which includes those who never answered and all other nonresponses and refusals) minus the nonsample numbers. This is virtually identical to the rate obtained in the CNEP survey. Interviews averaged 25 minutes. A maximum of 30 calls were made to each nonanswering or otherwise unresolved telephone number.

\section{Discussant Generator}

"From time to time, people discuss government, elections, and politics with other people. We'd like to know the first names or just the initials of people you talk with about these matters. These people might be from your family, from work, from the neighborhood, from some other organization you belong to, or they might be from somewhere else. Who is the person you've talked with most about politics? [Discussant \#1] Aside from this person, who is the person you've talked with most about politics? [Discussant \#2] Aside from anyone you've already mentioned, is there anyone else you've talked with about politics? [Discussant \#3]" If at any point the respondent could not give a name: "Well then, can you give the first name of the person with whom you were most likely to have informal conversations during the course of the past few months?"

\section{Media Source Generators}

Newspapers: "During the past week, did you read one or more newspapers? Which newspaper was that?"

Television News: "During the past week, did you watch any national news programs on television? What national news show was it that you watched? Which news program do you watch most often [if respondent names more than one]?"

News Magazines: "During the past week, did you read any news or current events magazines, such as U.S. News, Time, Newsweek, or some other news magazine? Which magazine was that?"

Political Talk Shows: "During the past week, did you happen to see a talk show on television or hear a talk show on the radio that included some discussion of political or social issues? What talk show was that?"

\section{Voluntary Associations and Workplace Generators}

Respondents were first asked about membership and participation in a list of types of voluntary associations, similar to those used in the General Social Survey. People who claimed membership in more than one such group were randomly assigned to one of the groups for a follow-up sequence, which asked identically worded questions parallel to those asked about the political discussants. These same five items were also asked with reference to coworkers, clients, or customers that employed respondents encountered in the workplace. The five items asking about voluntary associations produced an alpha of .74, and the same items referring to the workplace scaled at .72 .

\section{Five-Item Index of Exposure to Dissimilar Views}

1. "Compared with [named discussant, media outlet, voluntary association, or workplace], would you say that your political views are much the same [low], somewhat different, or very different [high]?"

2. "Do you think [named discussant, media outlet, voluntary association, or workplace] normally favors Republicans or Democrats, or both, or neither?" Scoring: same as respondent's partisanship (low), different from respondent's partisanship (high), or neither.

3. "Which presidential candidate, if any, does [named discussant, media outlet, voluntary association, or workplace] favor? Clinton, Dole, Perot, or some other candidate?" Scoring: same as respondent's preference (low), different from respondent's preference (high), or neither.

4. "Overall, do you feel [named discussant, media outlet, voluntary association, or workplace] shares most of your views on political issues [low], opposes them [high], or doesn't [it/person's name] do either one?"

5. Media version: "How often do you disagree with political views you [read/hear] about in/on the [media outlet]? 
Often [high], sometimes, rarely, or never [low]?" Discussant version: "When you discuss politics with [named discussant, voluntary association, or workplace], do you disagree often [high], sometimes, rarely or never [low]?"

\section{Closeness of Relationship}

"Is [named discussant] a close friend, just a friend, or just someone that you regularly come into contact with?" Spouses and relatives were coded into a fourth category.

\section{Frequency of Political Discussion}

Discussant Version: "When you talk with [named discussant], do you discuss politics a lot, some, a little, or very rarely?"

Media Version: "When you read/watch [named media outlet], do you read/watch stories about politics a lot, some, a little, or not at all?"

\section{Partisanship}

"Generally speaking, do you consider yourself a Republican, Democrat, independent, or what?"

\section{Political Interest}

"Some people seem to follow what's going on in government and public affairs most of the time, whether there's an election going on or not. Others aren't that interested. Would you say you follow what's going on in government and public affairs most of the time, some of the time, only now and then, or hardly at all?"

\section{Comfort with Controversy}

"When you were growing up, about how often did your [parents or guardians] take the position that certain topics are better left undiscussed? Often, sometimes, rarely, or never?" Scoring: $1=$ often $\ldots 4=$ never.

"How often did they have spirited discussions on controversial matters like politics or religion? Often, sometimes, rarely, or never?" Scoring: $1=$ never . . 4 = often.

The scale based on these two measures ranged from 2 to 8 .

\section{APPENDIX B. CROSS-NATIONAL ELECTION PROJECT SURVEY: AMERICAN AND BRITISH COMPONENTS}

\section{Design}

The American component of the CNEP combined a national survey with a survey of discussants named by main respondents and a content analysis of 40 newspapers conducted during the 1992 presidential election (for details and reliability of content measures, see Dalton, Beck, and Huckfeldt 1998; Dalton et al. 1998). The national survey was drawn from 40 county clusters around the United States (48 states), and the major newspaper read by residents in each of the counties was selected for content analysis. The British survey component was included as a module in the British General Election Cross-Section survey of 1992. Full details of the survey design and administration are given in Beck, Dalton, and Huckfeldt (1992) for the American survey, and Heath et al. (1992) for the British survey.

The newspaper sampling was done every third day and every Sunday from Labor Day to Election Day; a maximum of 27 days were coded for each paper, depending on its circulation pattern. On each coding day all stories that dealt directly with the presidential campaign and/or candidates and that appeared in the first half of the first news section were coded, as well as any special election pages and campaignrelated stories on the editorial pages. Coders were instructed as follows: "Code the overall content of the article that involves Bush, Quayle, or the Bush/Quayle campaign in terms of its favorability or unfavorability to the Bush campaign. Evaluate the article from the perspective of the Bush campaign and assess the content of the article from this perspective. In other words, would the Bush campaign like seeing this article in print?" (Dalton, Beck, and Huckfeldt 1992). The same instructions applied for Clinton/Gore and for Perot. We aggregated across all articles in a newspaper to obtain an average favorability/unfavorability score for each candidate. Newspapers were coded as favoring a candidate if his score was higher than that of the other two candidates and the differences were statistically significant at the $p<.05$ level.

\section{Discussant Generator}

"Now let's shift our attention to another area. From time to time, most people discuss important matters with other people. Looking back over the last six months, I'd like to know the people you talked with about matters that are important to you. Can you think of anyone? What is this person's first name? Is there anyone else you talk with about matters that are important to you?" Up to four names are accepted, then: "Aside from anyone you have already mentioned, who is the person you talked with most about the events of the recent presidential election campaign?"

\section{Perceived Disagreement with the Media}

Respondents were asked: "In the presidential election, which one of the candidates did you prefer?" They also were asked: "Which presidential candidate do you think [the newspaper] favored during the campaign, or didn't it favor any candidate?" The two responses were compared, and scoring was as follows: 0 = absolute agreement (respondent and newspaper concur), $1=$ mixed (either respondent or newspaper is independent/neutral), and 2 = disagreement (respondent and newspaper disagree). Television news magazine and talk show scoring was the same.

For the British sample, similar items were used with respect to the Conservative or Labour Party, and scoring was the same.

\section{Perceived Disagreement with Discussant}

A comparison was made between self-reported candidate support and the perceived support of Clinton, Bush, or Perot by the named discussants: "Which candidate do you think [discussant] supported in the presidential election this year?" Scoring: $0=$ absolute agreement (respondent and discussant concur), 1 = mixed (either respondent or discussant is independent/neutral), and $2=$ disagreement (respondent and discussant disagree).

A similar scale with respect to the Conservative and Labour parties was used for the British sample, and scoring was the same. To compare a single indicator of interpersonal exposure to disagreement, perceived disagreement was averaged across however many discussants a respondent named. 


\section{Independently Assessed Agreement/Disagreement}

For newspapers, assessment is based on the candidate that the respondent supported and the favorability score for the relevant newspaper as determined by content analysis. Scoring: $0=$ absolute agreement (respondent and newspaper concur), $1=$ mixed (either respondent or newspaper is independent/neutral), and $2=$ disagreement (respondent and newspaper disagree). For discussants, assessment is based on the respondent's self-report and the named discussants' self-reports, scored on the same three-point scale.

\section{Accuracy, Projection, and Contrast}

Accuracy, projection, and contrast were measured by the ability of main respondents to identify correctly the candidate supported by either their named discussants (as revealed in the discussant survey) or by their local newspaper (as revealed in content analysis). If the perceptions of the main respondent matched the independent assessment by coders or discussants, then they were scored as accurate. If the respondent judged the discussant or newspaper to be in more agreement than was the case, the respondent was scored as projecting. If the respondent judged the discussant or newspaper to be in less agreement than was the case, the respondent was scored as contrasting.

\section{American Partisanship}

(1) "Many people lean toward a particular political party for a long time, although they may occasionally vote for a different party. Do you generally lean toward a particular party?" (2) "If you had to choose, do you think of yourself as closer to the Republican or the Democratic party?" (3) "Taken altogether, how strongly or weakly do you lean toward the [Republican, Democratic] party? Would you say very strongly, fairly strongly, moderately, fairly weakly, or very weakly?"

\section{British Partisanship}

Form A: "Generally speaking, what do you think of yourself as [names of political parties]? Do you think of yourself as closer to one party? Which? How strong [name party] are you?" Form B: "Generally speaking, what do you think of yourself as?" "Which of the following parties do you feel a little closer to?" "How strong [name party] are you?"

\section{REFERENCES}

Altemeyer, Bob. 1996. The Authoritarian Specter. Cambridge, MA: Harvard University Press.

Arendt, Hannah. 1968. Between Past and Future: Eight Exercises in Political Thought. New York: Viking Press.

Barber, Benjamin. 1984. Strong Democracy: Participatory Politics for a New Age. Berkeley: University of California Press.

Beck, Paul Allen, Russell J. Dalton, and Robert Huckfeldt. 1992. Cross-National Election Studies: United States Study, 1992 (computer file) (Study \#6541). 2d ICPSR version. Columbus, OH: Paul A. Beck, Ohio State University/Irvine, CA: Russell J. Dalton, University of California/Bloomington, IN: Robert Huckfeldt, Indiana University [producers], 1993. Ann Arbor, MI: Inter-university Consortium for Political and Social Research [distributor], 1995.

Bellah, Robert N., Richard Madsen, William M. Sullivan, Ann Swidler, and Steven M. Tipton. 1985. Habits of the Heart: Individualism and Commitment in American Life. Berkeley: University of California Press.
Benhabib, Seyla. 1992. Situating the Self. New York: Routledge.

Bennett, Stephen, Bonnie Fisher, and David Resnick. 1994. "Speaking of Politics in the United States: Who Talks to Whom, Why, and Why Not." Paper presented at the annual meeting of the Midwest Political Science Association, Chicago.

Berlin, Isaiah. 1969. Four Essays on Liberty. New York: Oxford University Press.

Calhoun, Craig. 1988. "Populist Politics, Communication Media and Large Scale Societal Integration.” Sociological Theory 6 (3): 219 41.

Carey, James W. 1987. "The Press and the Public Discourse." The Center Magazine 20 (2): 4-32.

Curtice, John, Rüdiger Schmitt-Beck, and Peter Schrott. 1998. "Do the Media Matter?" Paper presented at the annual meeting of the Midwest Political Science Association, Chicago.

Dalton, Russell J., Paul Allen Beck, and Robert Huckfeldt. 1992. CNEP-USA Common Core Media Codebook. Typescript.

Dalton, Russell J., Paul Allen Beck, and Robert Huckfeldt. 1998. "Partisan Cues and the Media: Information Flows in the 1992 Presidential Election." American Political Science Review 92 (March): 111-26.

Dalton, Russell J., Paul Allen Beck, Robert Huckfeldt, and William Koetzle. 1998. "A Test of Media-Centered Agenda Setting: Newspaper Content and Public Interest in a Presidential Election." Political Communication 15 (November): 463-81.

Dewey, John. 1927. The Public and Its Problems. New York: Henry Holt.

Eliasoph, Nina. 1998. Avoiding Politics: How Americans Produce Apathy in Everyday Life. New York: Cambridge University Press.

Fabrigar, Leandre R., and Jon A. Krosnick. 1995. "Attitude Importance and the False Consensus Effect." Personality \& Social Psychology Bulletin 21 (5): 468-79.

Fearon, James. 1998. "Deliberation as Discussion." In Deliberative Democracy, ed. Jon Elster. New York: Cambridge University Press. Pp. 44-68.

Fishkin, James S. 1991. Democracy and Deliberation: New Directions for Democratic Reform. New Haven, CT: Yale University Press.

Freedman, Jonathan L., and David O. Sears. 1965. "Selective Exposure." In Advances in Experimental Social Psychology, vol. 2, ed. Leonard Berkowitz. New York: Academic Press. Pp. 58-98.

Frey, Dieter. 1986. "Recent Research on Selective Exposure to Information." In Advances in Experimental Social Psychology, vol. 19, ed. Leonard Berkowitz. New York: Academic Press. Pp. 41-80.

Frey, William H. 1995. "The New Geography of Population Shifts: Trends Toward Balkanization." In State of the Union: America in the 1990s, vol. 2, ed. Reynolds Farley. New York: Russell Sage. Pp. 271-336.

Giner-Sorolla, Roger, and Shelly Chaiken. 1994. "The Causes of Hostile Media Judgments." Journal of Experimental Social Psychology 30 (2): $165-80$.

Granovetter, Mark. 1973. "The Strength of Weak Ties." American Journal of Sociology 78 (May): 1360-80.

Habermas, Jürgen. 1989. The Structural Transformation of the Public Sphere. Cambridge. MA: MIT Press.

Hallin, Daniel C. 1986. The "Uncensored War": The Media and Vietnam. New York: Oxford University Press.

Harrison, Roderick J., and Claudette E. Bennett. 1995. "Racial and Ethnic Diversity." In State of the Union: America in the 1990s, vol. 2, ed. Reynolds Farley. New York: Russell Sage. Pp. 141-210.

Heath, Anthony, Rodger Jowell, John Curtice, Jack A. Brand, and James C. Mitchell. 1992. British General Election Cross-Section Survey, 1992 (computer file) (Study \#6453). ICPSR version. London, England: Social and Community Planning Research [producer]. Colchester, England: ESRC Data Archive/Ann Arbor, MI: Inter-university Consortium for Political and Social Research [distributors], 1996.

Huckfeldt, Robert, Paul Allen Beck, Russell J. Dalton, and Jeffrey Levine. 1995. "Political Environments, Cohesive Social Groups, and the Communication of Public Opinion." American Journal of Political Science 39 (4): 1025-54.

Huckfeldt, Robert, and John Sprague. 1995a. Citizens, Politics, and Social Communication: Information and Influence in an Election Campaign. New York: Cambridge University Press.

Huckfeldt, Robert, and John Sprague. 1995b. "Political Information and Communication among Citizens: Human Capital in an Elec- 
tion Campaign.” Proposal submitted to the National Science Foundation.

Katz, Elihu. 1968. "On Reopening the Question of Selectivity in Exposure to Mass Communications." In Theories of Cognitive Consistency: A Sourcebook, ed. Robert P. Abelson, Elliot Aronson, William McGuire, Theodore Newcomb, Milton Rosenberg, and Percy Tannenbaum. Chicago: Rand-McNally. Pp. 788-96.

Katz, Elihu. 1981. "Publicity and Pluralistic Ignorance: Notes on the Spiral of Silence." In Public Opinion and Social Change: For Elisabeth Noelle-Neumann, ed. Horst Baler, Hans Mathias Kepplinger, and Kurt Reuman. Weisbaden: Westdeutscher Verlag. Pp. $28-38$.

Katz, Elihu. 1996. "And Deliver Us from Segmentation." Annals of the American Academy of Political and Social Science 546: 22-33.

Katznelson, Ira, and Margaret Weir. 1986. "Working-Class Formation: Constructing Cases and Comparisons." In Working Class Formation, ed. Ira Katznelson and Aristide Zolberg. Princeton, NJ: Princeton University. Pp. 3-41.

Kenny, Christopher B. 1994. "The Microenvironment of Attitude Change." Journal of Politics 56 (August): 715-28.

Klapper, Joseph T. 1960. The Effects of Mass Communications. Glencoe, IL: Free Press.

Knight, Jack, and James Johnson. 1994. "Aggregation and Deliberation: On the Possibility of Democratic Legitimacy." Political Theory 22 (May): 277-96.

Krueger, Joachim, and Russell W. Clement. 1994. "The Truly False Consensus Effect: An Ineradicable and Egocentric Bias in Social Perception." Journal of Personality and Social Psychology 67 (4): 596-610.

Lazarsfeld, Paul F., Bernard Berelson, and Hazel Gaudet. 1944. The People's Choice. New York: Duell, Sloan and Pearce.

Levy, Frank. 1995. "Incomes and Income Inequality." In State of the Union: America in the 1990s, vol. 1: Economic Trends, ed. Reynolds Farley. New York: Russell Sage. Pp. 1-58.

Lippmann, Walter. 1922. Public Opinion. New York: Free Press.

Marcus, George E., John L. Sullivan, Elisabeth Theiss-Morse, and Sandra L. Wood. 1995. With Malice Toward Some: How People Make Civil Liberties Judgments. New York: Cambridge University Press.

Mansbridge, Jane. 1980. Beyond Adversary Democracy. New York: Basic Books.

McLeod, Jack M., and Steven H. Chaffee. 1972. "The Construction of Social Reality." In The Social Influence Process, ed. James Tedeschi. Chicago: Aldine-Atherton. Pp. 50-99.

Mill, John Stuart. [1859] 1956. On Liberty, ed. C.V. Shields. Indianapolis: Bobbs-Merril.

Mutz, Diana C. 1999. "Cross-Cutting Social Networks: Testing Democratic Theory in Practice." Paper presented at the annual meeting of the Midwest Political Science Association, Chicago.

Mutz, Diana C., and Jeffery J. Mondak. 1998. "Democracy at Work: Contributions of the Workplace Toward a Public Sphere." Paper presented at the annual meeting of the Midwest Political Science Association, Chicago.

Neuman, W. Russell. 1991. The Future of the Mass Audience. New York: Cambridge.

Nunn, Clyde Z., Harry J. Crockett, and J. Allen Williams. 1978. Tolerance for Nonconformity. San Francisco: Jossey-Bass.
Page, Benjamin I. 1996. Who Deliberates? Mass Media in Modern Democracy. Chicago: University of Chicago Press.

Sanders, Lynn M. 1977. "Against Deliberation.” Political Theory 25 (3): 347-76.

Schaeffer, Nora Cate. 1991. "Hardly Ever or Constantly? Group Comparisons Using Vague Quantifiers.” Public Opinion Quarterly 55 (Fall): 395-423.

Schiller, Herbert I. 1986. Information and the Crisis Economy. New York: Oxford University Press.

Schudson, Michael. 1981. Discovering the News. New York: Basic Books.

Schudson, Michael. 1982. "The Ideal of Conversation in the Study of Mass Media." In Inter/Media: Interpersonal Communication in a Media World, ed. Gary Gumpert and Robert Cathcart. New York: Oxford. Pp. 41-8.

Schudson, Michael. 1984. "Embarrassment and Erving Goffman's Idea of Human Nature." Theory and Society 13 (October): 633-48.

Schudson, Michael. 1995. The Power of News. Cambridge, MA: Harvard University Press.

Schudson, Michael. 1997. "Why Conversation Is Not the Soul of Democracy." Critical Studies in Mass Communication 14 (4): 297-309.

Sennett, Richard. [1977] 1992. The Fall of Public Man. New York: Alfred A. Knopf.

Sherif, Muzafer, and Carl I. Hovland. 1961. Social Judgment: Assimilation and Contrast Effects in Communication and Attitude Change. New Haven, CT: Yale University Press.

Simonson, Peter. 1996. "Dreams of Democratic Togetherness: Communication Hope from Cooley to Katz." Critical Studies in Mass Communication 13 (4): 324-42.

Stouffer, Samuel. 1955. Communism, Conformity, and Civil Liberties. New York: Doubleday.

Sullivan, John L., James Piereson, and George E. Marcus. 1982. Political Tolerance and American Democracy. Chicago: University of Chicago Press.

Sweeney, Paul D., and Kathy L. Gruber. 1984. "Selective Exposure: Voter Information Preferences and the Watergate Affair." Journal of Personality and Social Psychology 46 (6): 1208-21.

Turow, Joseph. 1997. Breaking Up America. Chicago: University of Chicago Press.

Ulbig, Stacy G., and Cary L. Funk. 1999. "Conflict Avoidance and Political Participation.” Political Behavior 21 (3): 265-82.

Vallone, Robert P., Lee Ross, and Mark R. Lepper. 1985. "The Hostile Media Phenomenon: Biased Perception and Perception of Media Bias in Coverage of the Beirut Massacre." Journal of Personality and Social Psychology 49 (3): 577-85.

Weaver, David H., and G. Cleveland Wilhoit. 1996. The American Journalist in the 1990s: U.S. News People at the End of an Era. Mahwah, NJ: Lawrence Erlbaum.

Watts, Mark D., David Domke, Dhavan V. Shah, and David P. Fan. 1999. "Elite Cues and Media Bias in Presidential Campaigns: Explaining Public Perceptions of a Liberal Press." Communication Research 26 (2): 144-75.

Zaller, John. 1992. The Nature and Origins of Mass Opinion. New York: Cambridge University Press.

Zillmann, Dolf, and Jennings Bryant. 1985. Selective Exposure to Communication. Hillsdale, NJ: Lawrence Erlbaum. 